\title{
Epidemiology of unintentional drowning and near-drowning in Denmark in 1995
}

\author{
Peter Lindholm, Jens Steensberg
}

\begin{abstract}
Objectives-To determine the pattern of accidental drowning and near-drowning in Denmark.

Design-Prospective study of all cases of accidental drowning and near-drowning during one year.

Setting-Denmark, 1995.

Subjects-All patients brought to Danish hospitals after incidents of unintentional near-drowning or cooling in water and all fatal cases.

Main outcome measures-Number of near-drowned patients reported prospectively by hospital departments supplemented by cases reported after requests based on the National Patient Register. Number of drownings reported by public health medical officers (as medical examiners), institutes of forensic medicine, and hospitals.

Results-Sixty three (38\%) of 167 unintentionally immersed persons died: eight $(17 \%)$ of 47 children and $55(46 \%)$ of 120 adults. The annual incidence of serious immersion events in children leading to hospital contact was 5.2/100 000; mortality was $0.7 / 100000$. For adult males the annual incidence of serious unintentional immersions was $4.3 / 100000$ and for females 1.2/100 000. For foreigners the risk was three to four times higher than for Danes.

Conclusions-More attention should be paid to the risk of drowning in children, adult males, and foreigners.

(Injury Prevention 2000;6:29-31)
\end{abstract}

Keywords: drowning; near-drowning; epidemiology

In Denmark, deaths from drowning or cooling in water represent nearly $2 \%$ of all unintentional deaths. A retrospective study of 349 cases of unintentional drowning or cooling in water occurring in Denmark from 1989-93 found that $86 \%$ were males, and $13 \%$ were children aged $0-14$ years. ${ }^{1}$ During these years the annual number of unintentional drownings varied between 59 and 86 in a population of approximately five million.

In Denmark, the risk of drowning in children has decreased during the last decades. In the late 1960 s $30-40$ children died annually in this manner, ${ }^{2}$ falling to around 10 in the early 1990s. In the period 1976-85, approximately $12 \%$ of unintentional deaths in children were drownings. ${ }^{3}$ According to the official 1995 statistics, seven of 21 accidental deaths in 1-4 year old children were drownings compared with six that were transport related. ${ }^{4}$ The annual number of child drownings in Denmark in 1989-93 was $1.1 / 100000,{ }^{1}$ and in 1995 $0.7 / 100000$; this is similar to UK experience in the late 1980s. ${ }^{5}$ Higher mortality figures have been reported from Norway and Iceland: 2.2 and 2.0/100 000, respectively. ${ }^{67}$

Little is known of the overall pattern of water immersion incidents and cases of neardrowning. In the period 1976-84 drowning was the fourth leading cause of unintentional injury death in Los Angeles County, with an annual rate of $2.36 / 100000$ persons. $^{8}$ In the United States, drowning is now the single leading cause of injury death in children 1-4 years of age, surpassing both motor vehicle occupant and pedestrian deaths. ${ }^{9}$ In England and Wales, in the late 1980s, the annual incidence of hospitalized children after near-drowning was 1.5/ 100000 and almost half of these children died. ${ }^{5}$ The reported mortality was lower in other studies-for example, Birmingham, Alabama (28\%) and Japan (22\%), probably depending on the selection of cases. ${ }^{11}$

One of the functions of Danish public health medical officers is to act as medical examiners. Impressions over several years in this function of inspecting the corpses of drowning victims and writing the death certificates based on police reports stimulated the interest of one author (JS) in improving our knowledge of the epidemiology of unintentional drowning with a view to the prospects for prevention. The other author (PL) was already doing a study on drowning and near-drowning in one Danish county. The present study was undertaken, supplementing the retrospective study of fatalities, ${ }^{1}$ to obtain a nationwide estimate of unintentional drowning and cases of neardrowning during a one year period. Data on treatment and prognosis will be reported elsewhere.

\section{Methods}

We gathered data prospectively on all patients brought to Danish hospitals after incidents of near-drowning (submersio) or cooling (immersio frigida) in water, and all fatal cases with unintentional drowning or cooling in water as the cause of death. The same survey form was used in the retrospective study of five years of accidental drowning. ${ }^{1}$

In December 1994 all Danish hospital departments of anaesthesiology, internal medicine, pediatrics, and orthopedic surgery (responsible for casualty departments) during the calendar year 1995 were asked to report cases of immersion in water, near-drowning, and drowning. In May 1995 a reminder was sent to 
Table 1 Cases of unintentional near-drowning and fatal drowning or cooling in water in Denmark in 1995 by age and gender

\begin{tabular}{|c|c|c|c|c|c|c|}
\hline \multirow[b]{2}{*}{ Age (years) } & \multicolumn{2}{|l|}{ Male } & \multicolumn{2}{|l|}{ Female } & \multicolumn{2}{|l|}{ Total } \\
\hline & No & $\begin{array}{l}\text { Incidencel } \\
100000\end{array}$ & No & $\begin{array}{l}\text { Incidencel } \\
100000\end{array}$ & No $(\%)$ & $\begin{array}{l}\text { Incidencel } \\
100000\end{array}$ \\
\hline $0-4$ & 14 & 8.6 & 12 & 7.0 & $26(15.6)$ & 7.8 \\
\hline $5-9$ & 8 & 5.6 & 6 & 4.0 & $14(8.4)$ & 4.8 \\
\hline $10-14$ & 5 & 3.7 & 2 & 1.4 & $7(4.2)$ & 2.6 \\
\hline $15-24$ & 12 & 3.5 & 2 & 0.6 & $14(8.4)$ & 2.0 \\
\hline $25-34$ & 15 & 3.8 & 4 & 1.0 & 19 (11.4) & 2.4 \\
\hline $35-44$ & 16 & 4.4 & 5 & 1.3 & $21(12.6)$ & 2.8 \\
\hline $45-54$ & 25 & 6.7 & 3 & 0.8 & $28(16.8)$ & 3.7 \\
\hline $55-64$ & 8 & 3.1 & 1 & 0.4 & $9(5.4)$ & 1.8 \\
\hline $65-74$ & 12 & 5.0 & 5 & 2.5 & $17(10.2)$ & 3.9 \\
\hline $75-84$ & 5 & 3.0 & 5 & 4.7 & $10(6.0)$ & 3.6 \\
\hline 85-94 & 1 & 1.7 & 1 & 4.2 & $2(1.2)$ & 2.4 \\
\hline Total (\%) & $121(72.5)$ & 4.6 & $46(27.5)$ & 1.8 & $167(100)$ & 3.2 \\
\hline
\end{tabular}

these departments. The medicostatistical unit of the National Board of Health was later asked to extract data from the National Patient Register identifying all patients, including outpatients, with the relevant diagnoses. On this basis hospitals in early 1997 were asked to report cases that had not already been reported to the investigators. Information received later than 1 July 1997 has not been included. Because fatal cases would frequently not be registered by hospitals, all regional public health medical officers (acting as medical examiners), and the three university institutes of forensic medicine, were asked to report during 1995 all cases of unintentional drowning or cooling in water. Reminders were sent in April and October 1995. Data were transferred from the survey forms to a computerized database.

The study was approved by the Ministry of Justice, the Registry Inspection, and the regional committees of ethics.

\section{Results}

A total of 167 cases of unintentional neardrowning and fatal drowning or cooling in water were registered: $47(28.1 \%)$ children and 120 adults. Twenty nine self inflicted cases reported by hospitals, one case the result of violence, and 13 cases with unknown background were omitted.

Table 1 shows the distribution by age and gender. The surviving victims must be considered to have been exposed at least to a potentially serious incident as they were brought to a hospital after the immersion event. One hundred and twenty one $(72.5 \%)$ were males, and among the 47 children a small predominance of boys was found $(57.5 \%)$. The incidence/100 000 population was 3.2 ; for adult males 4.3; for adult females 1.2; and for children 5.2/100 000 .

Thirty four persons (11 children) were not of Danish nationality $(20.6 \%$ of 165 cases with information). The total number of foreign nationals resident in Denmark is known. ${ }^{4}$ If the number of bed nights for visiting foreigners for the year 1995 (Danmarks Turistråd, 1998) divided by 365 is added, the incidence of serious drowning incidents 100000 foreigners was 12.5 (in children 16.9), that is, the overall risk for foreigners was three to four times higher than for Danes.
Eight of the 47 children (17\%) and 57 of the 120 adults $(47.5 \%)$ died. Three children $(6.4 \%)$ survived with lasting disability. The mortality for children was 0.7 and for adults $1.2 / 100000$.

Almost half of the 47 children were alone when the event took place. Existing disease that might be of causal importance was identified in three cases: psychomotor retardation (2) and asthma (1), but there was no case of epilepsy. Child events most frequently occurred on Saturdays $(10 ; 23 \%$ of 44 cases with information). One half of those involving children (23) took place in some sort of artificial water basin: 10 of these in supervised public pools, six in private pools, and seven in garden fish ponds. Three occurred in bath tubs, 12 when the child was bathing or swimming (30\% of 40 cases with information), but in only three cases did this happen at a beach. Five of the 11 children that were not of Danish nationality belonged to families of immigrants or asylum applicants (mean age 8 years; four incidents occurred in public pools) and six to tourist families (mean age 4 years).

In $35(29.2 \%)$ of the 120 adult cases it was positively stated that the person was alcohol intoxicated. For 36 persons it was stated that existing disease, including having a chronic alcohol problem, might have acted as a causative factor (no information in 30 cases). Data on day of the week were lacking in eight cases, but 33 events $(29.5 \%$ of those with information) occurred on Saturdays. The location was not known in six cases; 71 occurred at beaches, in open sea, or lakes/watercourses; 28 in harbours; and 10 in swimming pools. In almost half of the cases the activity of the victim was not stated but the most frequently mentioned activities were bathing and leisure fishing from a boat $(48 \%$ and $21 \%$ respectively of cases with information). Twenty three of the adults were foreigners (91\% were 15-54 years old $v 57 \%$ of Danish adults), two were seamen, and the other 21 presumably tourists. Of these, seven were bathing or swimming (three at beaches), six were leisure fishing, and five were in cars that drove into harbour basins.

\section{Discussion}

Our subjects include all patients brought to a Danish hospital in 1995 after unintentional 
incidents of near-drowning or cooling in water and all fatalities. We found 57 adults who died from accidental drowning or cooling in water, compared with 31 cases of drowning and 18 of cooling (a few of which may not have been water related) reported in the official 1995 mortality statistics. ${ }^{4}$ Our follow up of the prospectively collected cases, based on data from the National Patient Register, means that very few cases of near-drowning reaching hospitals could be missing.

The predominance of males as victims of accidental submersion has been shown by many authors. ${ }^{6}{ }^{1213}$ Results of a telephone interview study performed in the United States illustrated the fact that men have greater exposure to aquatic environments, and especially to high exposure activities, and that they drink more alcohol than women when on or near the water. ${ }^{14}$ Three quarters of the children who drowned in Denmark from 1989-93 were boys, ${ }^{1}$ but in this study, that includes neardrowning, their predominance over girls was small.

The annual incidence of children brought to hospitals in our study was 5.1/100 000 and the number of children suffering from serious immersion incidents was six times higher than the number of fatalities. A UK study excluded children who were discharged from the accident department after minor submersion events. $^{5}$ This, however, only partly explains their lower incidence of $1.5 / 100000$, as only half of our 47 children were sent home the same day or within 24 hours. Our mortality rate was similar to the UK rate, so that some under-reporting in the British study might be the reason for the difference.

Although it was not possible to adhere to a strict definition of "foreigner" as opposed to "Danish", we are convinced that the three to four times higher risk of foreigners experiencing a submersion incident is real. A Dutch study found that $16 \%$ of their victims were foreigners compared with $21 \%$ in our study. ${ }^{13}$ Twenty nine per cent of the foreign nationals resident in Denmark come from parts of Europe and other continents with cultures and lifestyles that differ from those in northwestern Europe, which may increase their risk. To this should be added that foreign tourists are often inexperienced with the extensive Danish waters.

In more than one fourth of the adult cases it was positively stated that the person was under the influence of alcohol. In the 1989-93 study of fatalities it was judged that between one third and one half of the adult cases were related to alcohol. ${ }^{1}$ In American and Australian studies of drownings positive blood alcohol tests were found in $47 \%$ of adults ${ }^{12}$ and $37 \%$ of adult males. ${ }^{15}$

One half of the child cases occurred in some sort of artificial water basin in accordance with British experience. ${ }^{5}$ In Alabama, pools ac- counted for $61 \%$ of hospitalized neardrownings in children. ${ }^{16}$ In 1974 obligatory fencing around private swimming pools became part of the Danish Building Regulations, but these rules were dropped 10 years later as the authorities felt that they did not prevent drownings and might even lead to a false sense of security.

Experience from this study emphasizes that children between 1 and 4 years of age must be under permanent adult supervision if open water bodies are nearby. Fish or garden ponds could be eliminated and private swimming pools fenced.

Adult males are at particular risk of drowning. More systematic use of life jackets by males when fishing from boats or during other forms of leisure boating would prevent many fatalities. However, the predominant risk factor in men is the use of alcohol. Besides repeatedly emphasizing the hazard for persons who have been drinking, the only way forward seems to be society's general efforts to deal with the alcohol problem.

The higher risk in people from other cultures and tourists calls for improved information aimed at specified subgroups.

The Danish National Board of Health has given financial support to this study, and its medicostatistical unit kindly provided data from the National Patient Register. Niels Bloch Jespersen, Regional Public Health Medical Officer, Hillerød, has given invaluable support in the computer handling of the regional public health medical officers, and the three of forensic medicine is gratefully acknowledged.

1 Steensberg J. Epidemiology of accidental drowning in Denmark 1989-1993. Accid Anal Prev 1998;30:755-62.

2 Buhl L. Drukneulykker blandt børn i private svømmebassiner 1965-1974. Ugeskr Leeger 1977;139:1923-5.

3 Jørgensen IM. The epidemiology of fatal unintentional child injuries in Denmark. Dan Med Bul 1995;42:285-90.

4 Sundhedsstyrelsen. Dødsårsagerne $i$ 1994 og 1995. SundSundhedsstyrelsen. Dødsårsagerne $i 1994$ og 1995. Sund-
hedsstatistikken 1997:3. København: Sundhedsstyrelsen, hedsstatist 1997.

5 Kemp A, Sibert JR. Drowning and near drowning in children in the United Kingdom: lessons for prevention. $B M F$ 1992;304:1143-6.

6 Skulberg A. Drukning (dissertation). Oslo: University of Oslo, 1987 (mimeographed)

7 Ludvigsson P, Storgaard H, Gudmundsdottir GB. Study on child drowning in Iceland 1984-1993. Proceedings of the Third International Conference Injury Prevention and Control. Melbourne, Australia, 1996: 152

8 O'Carroll PW, Alkon E, Weiss B. Drowning mortality in Los Angeles County, 1976 to 1984 . $\mathcal{F A M A} 1988 ; 260: 380-3$.

9 Smith GS. Drowning prevention in children: the need for new strategies. Inj Prev 1995;1:216-7.

10 King WD, Joseph M. Epidemiology of immersion-injury hospitalizations. Proceedings of the Third International
Conference Injury Prevention and Control. Melbourne, Conference Injury P
Australia, 1996: 278 .

11 Mizuta R, Tanaka T, Yamanaka T. Childhood drownings and near-drownings in Japan. Proceedings of the Third International Conference Injury Prevention and Control. Melbourne, Australia, 1996: 279 .

12 Dietz PE, Baker SP. Drowning. Epidemiology and prevention. Am $\mathcal{F}$ Public Health 1974;64:303-12.

13 Bierens JJLM, van der Velde EO, van Berkel M, et al. Submersion cases in the Netherlands. Ann Emerg Med 1989;18:366-73.

14 Howland J, Hingson R, Mangione TW, et al. Why are most drowning victims men? Sex differences in aquatic skills and behaviors. Am f Public Health 1996;86:93-6.

15 Plueckhahn VD Alcohol and accidental drowning. A 25-year study. Med F Aust 1984;141:22-5.

16 King WD, Joseph M. Epidemiology of immersion-injury hospitalizations. Proceedings of the Second World Conference on Injury Control. Atlanta, Georgia, 1993: 278-9. 